\title{
LA INJUSTICIABILIDAD
}

Este término bastante novedoso y muy aplicable a las sociedades latinoamericanas como la colombiana, literalmente significaría la no justiciabilidad, es decir, la no aplicación de justicia en un caso determinado. Es lo opuesto a justiciabilidad que se refiere a la posibilidad de que un problema sea dirimido en foros judiciales o cuasi judiciales.

La injusticiabilidad se refleja cuando a un ciudadano se le niega la posibilidad de que le reconozcan el valor justicia y obtenga una decisión judicial que resuelva un litigio de tal manera que la controversia no está juzgada. En este sentido, la noción de injusticia permite captar, a pesar de su diversidad, todos los puntos ciegos de la ley y la justicia.

La doctrina europea ha desarrollado recientemente esta temática en una obra colectiva titulada "L'injusticiabilité : émergence d'une notion ?Etudes publiées en hommage au Professeur Jacques Leroy Pierre Serrand", obra publicada por la Universidad Jagellonne (Cracovia - Polonia) y dirigida por el profesor Piotr Szwedo.

En esta publicación se distinguen las justicias externas y las internas. En el primer caso se da ante la imposibilidad de lograr justicia por causas ajenas al propio conflicto. Sería el evento, por ejemplo, cuando la apelación ante un juez es inadmisible o en lo que respecta al litigio de resoluciones, el acto impugnado estaba fuera de plazo o el demandante no tiene un interés que le otorgue legitimación.

En el segundo caso, la imposibilidad o dificultad de obtener justicia se explica por la propia naturaleza de la disputa. Serían los eventos de oscuridad de la ley o de las lagunas jurídicas. Este sería un evento de vacío normativo que tiene la desviación de omitir en su texto la solución concreta de una determinada situación, lo que constriñe a quienes aplican dicha norma, al empleo de técnicas de interpretación sustitutivas con las cuales se consiga respuesta efectiva a la problemática legal.

La injusticia puede ser consecuencia de la aplicación de normas legales. Este es el caso, por ejemplo, de la injusticia que disfrutan los autores de delitos prescritos, los evasores de impuestos que no son sancionados o lo servidores públicos corruptos que no reciben la sanción disciplinaria por argucias jurídicas, ineficacia del sistema o por fisuras del sistema legal. 
En situaciones como esta, la injusticia es comparable al concepto de lex imperfecta, descrito en el derecho romano por Ulpianus. Entonces es posible pensar que estamos en escenarios prohibidos por la ley o no prescritos en ella, sin que la norma consagre alguna consecuencia frente a esta situación.

En el caso colombiano la ausencia de justicia es bastante frecuente y se refleja en las preocupantes cifras estadísticas sobre congestión, demora en los procesos judiciales e impunidad.

Sobre este último aspecto, en el informe anual sobre la situación de derechos humanos en Colombia ${ }^{1}$, la Oficina del Alto Comisionado de la ONU sostuvo que en el año 2018 el homicidio aumentó en el 49 por ciento de los municipios y resaltó la existencia de los altos niveles de impunidad. En dicho documento, la ONU recordó que tal fenómeno en este país ha oscilado entre el 86 y el 94 por ciento, y si bien reconoce los recientes esfuerzos de la justicia para atender el problema, se hace un llamado a las autoridades para redoblar acciones que tiendan a reducir las tasas de impunidad.

El gobierno colombiano tiene como tarea pendiente una gran reforma a la justicia que permita corregir esa disfunción en uno de los servicios y deberes más grandes de un Estado. Mejorar el acceso y funcionamiento de la justicia es indispensable para optimizar la seguridad, el goce de los derechos y la materialización de un verdadero Estado Social de Derecho.

\author{
Germán Alfonso López Daza (PhD). \\ Editor \\ Revista Jurídica Piélagus
}

\footnotetext{
${ }^{1}$ Consejo de Derechos Humanos 40ำ período de sesiones 25 de febrero a 22 de marzo de 2019. Tema 2 de la agenda Informe anual del Alto Comisionado de las Naciones Unidas para los Derechos Humanos e informes de la Oficina del Alto Comisionado y del Secretario General.
} 